\title{
OPTIMIZATION OF FRICTION STIR WELDING PARAMETERS FOR JOINING ALUMINUM ALLOY 6105 USING TAGUCHI TECHNIQUE
}

\author{
Amit Kumar1, Vijay Kr. Sharma ${ }^{2}$, Jai Singh ${ }^{3}$, \\ ${ }^{I}$ Student, M.Tech, Manufacturing System, E-max GOI, Gola, Ambala, India \\ ${ }^{2}$ Assistant Professor, Department of Mechanical Engineering, E-max GOI, Gola, Ambala, India \\ ${ }^{3}$ Professor \& Head, Department of Mechanical Engineering, E-max GOI, Gola, Ambala, India
}

\begin{abstract}
This investigation represents the effects of parameters of friction stir welding on tensile strength and hardness during welding of Aluminium Alloy 6105. A fabricated FSWM set up was used for welding. A high carbon steel tool having $18 \mathrm{~mm}$ shoulder diameter and $5.5 \mathrm{~mm}$ pin diameter has been used. It was noted that for the friction stir welding of aluminium alloy 6105 , maximum tensile strength is $0.0912 \mathrm{KN} / \mathrm{mm}^{2}$, which is obtain at $1250 \mathrm{rpm}$ tool rotation speed, $25 \mathrm{~mm} / \mathrm{min}$ welding speed and $0^{0}$ tilt angle. It was also noted that the maximum vicker hardness is 65.7 which is obtain at $1550 \mathrm{rpm}$ rotational speed, $35 \mathrm{~mm} / \mathrm{min}$ welding speed and $0.5^{0}$ tilt angle.
\end{abstract}

Keywords: Friction stir welding, Aluminium alloy 6105, tensile strength, hardness, Taguchi L $_{9}$ orthogonal array

\section{INTRODUCTION}

Friction stir welding is a solid state joining process in which material is welded without melt and recast. It is mostly used in the construction of railway carriages worldwide, automation industries, fabrication work, construction of marine vessels and for the large production of aluminium panels, which are prepared from aluminium extrusions.[1] Friction stir welding mostly suitable for joining for dissimilar aluminium alloys.

From the study of published available literature, it is noticed that friction stir welding seems to be more advantageous as compare to other welding technique. It offer several advantages such as good weld appearance, Improve strength, ductility, resistance to corrosion, fine grain structure and welded surface is free of porosity with lower distortion. [2,3,4] In FSW process, a non consumable rotating tool, consisting of a shoulder and a profile probe or pin, is forced down into the joint line under conditions where the frictional heating is sufficient to raise the temperature of the material to the range where it is plastically deformed. Study report that different input parameters like tool rotational speed, welding speed and tilt angle have an important effect on tensile strength and hardness of the weld joint [5-8]. But the optimization of friction stir welding parameters of aluminium alloy 6105 using taguchi technique has not been reported yet.

This paper is reported effect of various input parameters of friction stir welding on aluminium alloy 6105 .

\section{EXPERIMENTAL PLANNING}

The friction stir welding process is performed on vertical milling machine. Friction stir welds were made on the plates of aluminum alloy 6105. The plates were cut from the sheet of aluminum alloy material. Single- pass friction stir butt joint was made using a friction stir welding tool which was fabricated from a material H13. The total length of the tool is $125 \mathrm{~mm}$. The shoulder diameter is $18 \mathrm{~mm}$ and pin diameter is $5.5 \mathrm{~mm}$. The welded plate is in rectangular shape with a size of $150 \mathrm{~mm} \times 100 \mathrm{~mm} \times 6 \mathrm{~mm}$. The used welding parameters are tool rotational speed, welding speed and tool tilt angle. The weld plates are suitably clamped in the suitable fixture for hold the plates in such a manner that both the plates cannot move from its position during the welding process. The fixture provides a base to place the plates for ensuring the proper flat position for the welding process. Many conditions are seen during the welding process when tool rotational speed is low, then welding become hard and welding process produce noise due to the improper heating and mixing of the material. The heat is also effect the type of chips produced during the welding process

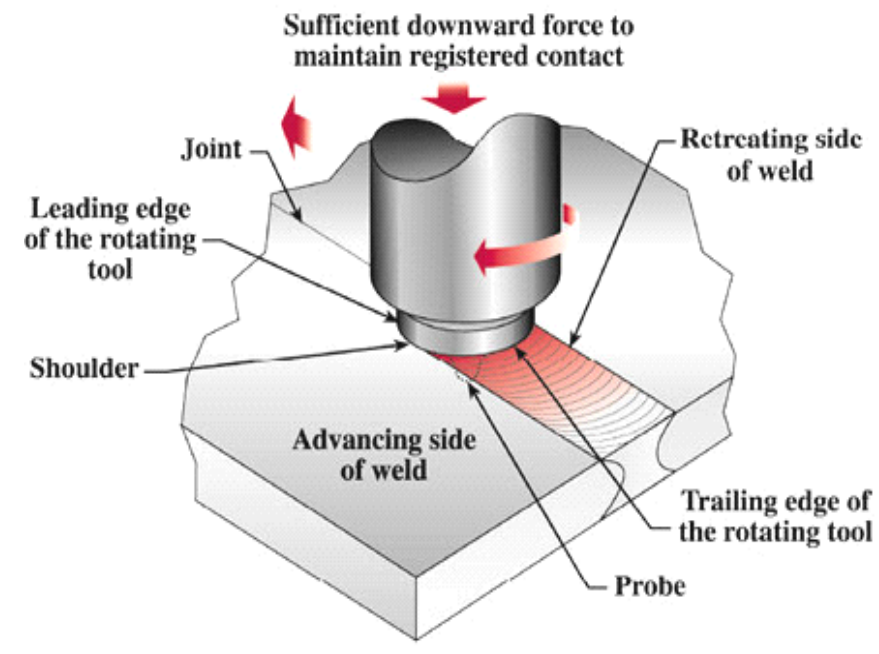

Fig. 1 Friction Stir Welding 


\section{RESULT AND DISCUSSION}

The effects of process parameters of developed Friction Stir Welding setup such as the tool rotational speed, welding speed and tilt angle on TS $\left(\mathrm{KN} / \mathrm{mm}^{2}\right)$ and hardness during welding of aluminium alloy 6105 are analyses through various graphs.

\subsection{Effect of Various Parameters on Tensile Strength}

Table 1 represent the experiment results obtained during the friction stir welding of aluminium alloy 6105. The result i.e. Tensile Strength and S/N Ratio were obtained at variation of the tool rotational speed 950 to $1550 \mathrm{rpm}$, welding speed i.e. from 25 to $45 \mathrm{~mm} / \mathrm{min}$ and tilt angle i.e. from 0 to 1 degree.

Table 1: Testing result of Tensile Strength and Signal to Noise Ratios

\begin{tabular}{|l|l|l|l|l|l|}
\hline S. No & $\begin{array}{l}\text { Rotational } \\
\text { speed(rpm) }\end{array}$ & $\begin{array}{l}\text { Welding } \\
\text { speed(mm/min) }\end{array}$ & $\begin{array}{l}\text { Tilt angle } \\
(\mathbf{d e g r e e})\end{array}$ & $\begin{array}{l}\text { Tensile strength } \\
\left(\mathbf{K N} / \mathbf{m m}^{2}\right)\end{array}$ & SNRA \\
\hline 1 & 950 & 25 & 0 & 0.085 & -21.4116 \\
\hline 2 & 950 & 35 & 0.5 & 0.078 & -22.1581 \\
\hline 3 & 950 & 45 & 1 & 0.067 & -23.4785 \\
\hline 4 & 1250 & 25 & 0.5 & 0.082 & -21.7237 \\
\hline 5 & 1250 & 35 & 1 & 0.084 & -21.5144 \\
\hline 6 & 1250 & 45 & 0 & 0.087 & -21.2096 \\
\hline 7 & 1550 & 25 & 1 & 0.079 & -22.0475 \\
\hline 8 & 1550 & 35 & 0 & 0.076 & -22.3837 \\
\hline 9 & 1550 & 45 & 0.5 & 0.072 & -22.8534 \\
\hline
\end{tabular}

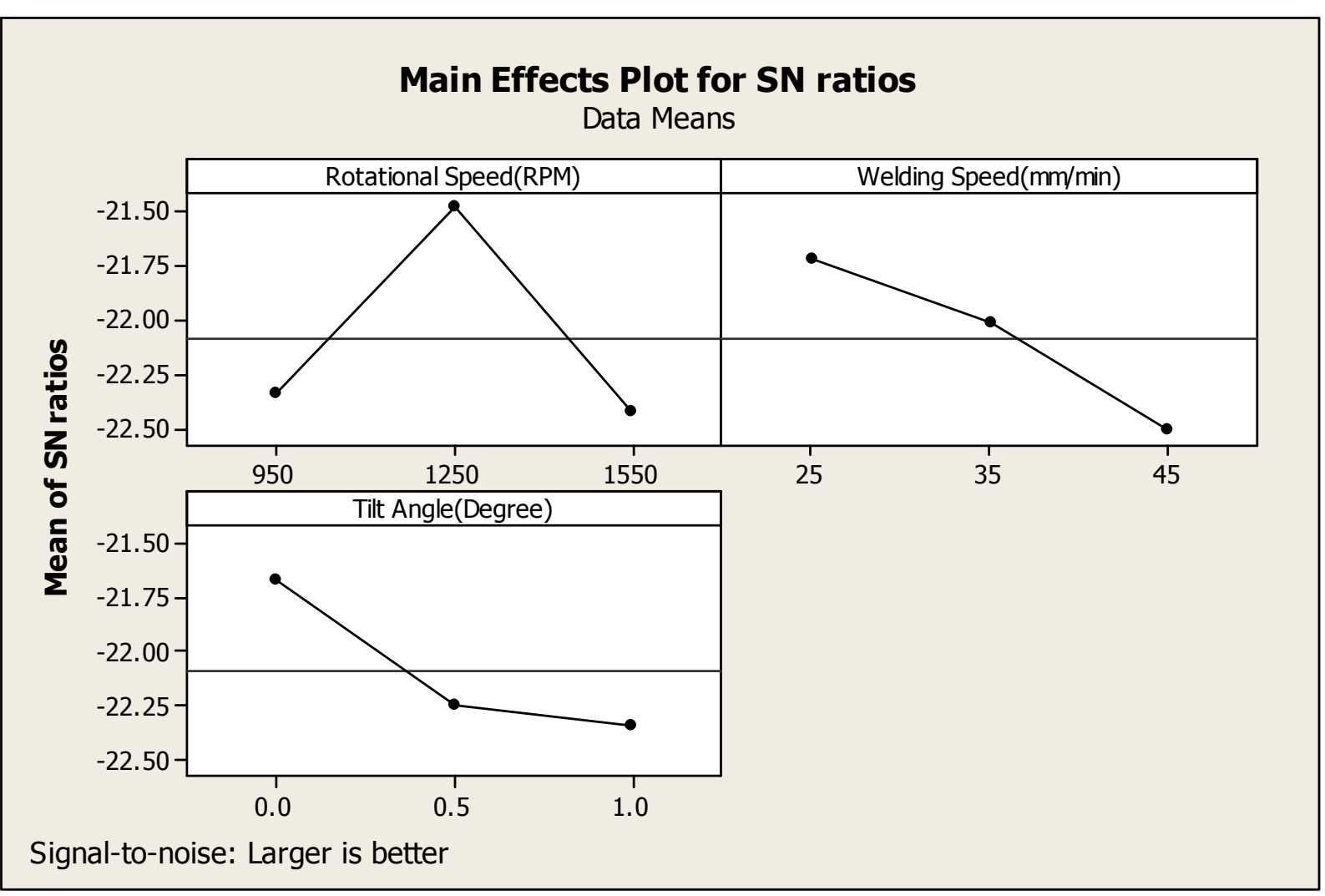

Fig. 2: Mean effect plots for means on Tensile Strength

Figure 2 shows effect of various FSW process parameters on the mean of S/N Ratio of tensile strength plotted utilizing the welding result obtained. From the figure, it is observed that the mean value of the mean of $\mathrm{S} / \mathrm{N}$ Ratio of tensile strength rises constantly by increasing the value of rotational speed from 950 to $1250 \mathrm{rpm}$ and after that the mean of $\mathrm{S} / \mathrm{N}$
Ratio of TS is decreased by increasing the rotational speed from 1250 to $1550 \mathrm{rpm}$. The mean of $\mathrm{S} / \mathrm{N}$ ratio of TS is decreased by increasing the welding speed from 25 to 35 $\mathrm{mm} / \mathrm{min}$ and from 35 to $45 \mathrm{~mm} / \mathrm{min}$. The mean of S/N Ratio of TS is decreased by increasing the tilt angle from 0 to 0.5 degree and from 0.5 to 1 degree 
Table 2 Response table for Signal to Noise Ratios Larger is better

\begin{tabular}{|l|l|l|l|}
\hline Level & Rotational speed(rpm) & Welding speed(mm/min) & Tilt angle (degree) \\
\hline 1 & -22.35 & -21.73 & -22.82 \\
\hline 2 & -21.48 & -22.18 & -22.09 \\
\hline 3 & -22.43 & -22.36 & -22.35 \\
\hline Delta & 0.95 & 0.63 & 0.52 \\
\hline Rank & 1 & 2 & 3 \\
\hline
\end{tabular}

Table 2 shows the ranking of FSW parameters for optimizing the tensile strength. It can be observed that rotational speed has the largest effect on the tensile strength of aluminium alloy 6105. The tilt angle has the smallest effect on the tensile strength.
3.2 Effect of various parameters on Vicker Hardness

Table 3 show the experiment results obtained during the friction stir welding of aluminium alloy 6105 . The result i.e. Vicker Hardness and S/N Ratio were obtained at variation of the tool rotational speed 950 to $1550 \mathrm{rpm}$, welding speed i.e. from 25 to $45 \mathrm{~mm} / \mathrm{min}$ and tilt angle i.e. from 0 to 1 degree

Table 3: Testing result of Vicker hardness and Signal to Noise Ratios

\begin{tabular}{|c|c|c|c|c|c|}
\hline S. No & $\begin{array}{l}\text { Rotational } \\
\text { speed(rpm) }\end{array}$ & $\begin{array}{l}\text { Welding } \\
\operatorname{speed}(\mathrm{mm} / \mathrm{min})\end{array}$ & $\begin{array}{l}\text { Tilt angle } \\
\text { (degree) }\end{array}$ & $\begin{array}{l}\text { Avg. Vicker } \\
\text { hardness }\end{array}$ & SNRA \\
\hline 1 & 950 & 25 & 0 & 51 & 34.1514 \\
\hline 2 & 950 & 35 & 0.5 & 55 & 34.8073 \\
\hline 3 & 950 & 45 & 1 & 36 & 31.1264 \\
\hline 4 & 1250 & 25 & 0.5 & 54 & 34.6479 \\
\hline 5 & 1250 & 35 & 1 & 56 & 34.9638 \\
\hline 6 & 1250 & 45 & 0 & 36 & 31.1261 \\
\hline 7 & 1550 & 25 & 1 & 44 & 32.8691 \\
\hline 8 & 1550 & 35 & 0 & 57 & 35.1175 \\
\hline 9 & 1550 & 45 & 0.5 & 59 & 35.4170 \\
\hline
\end{tabular}




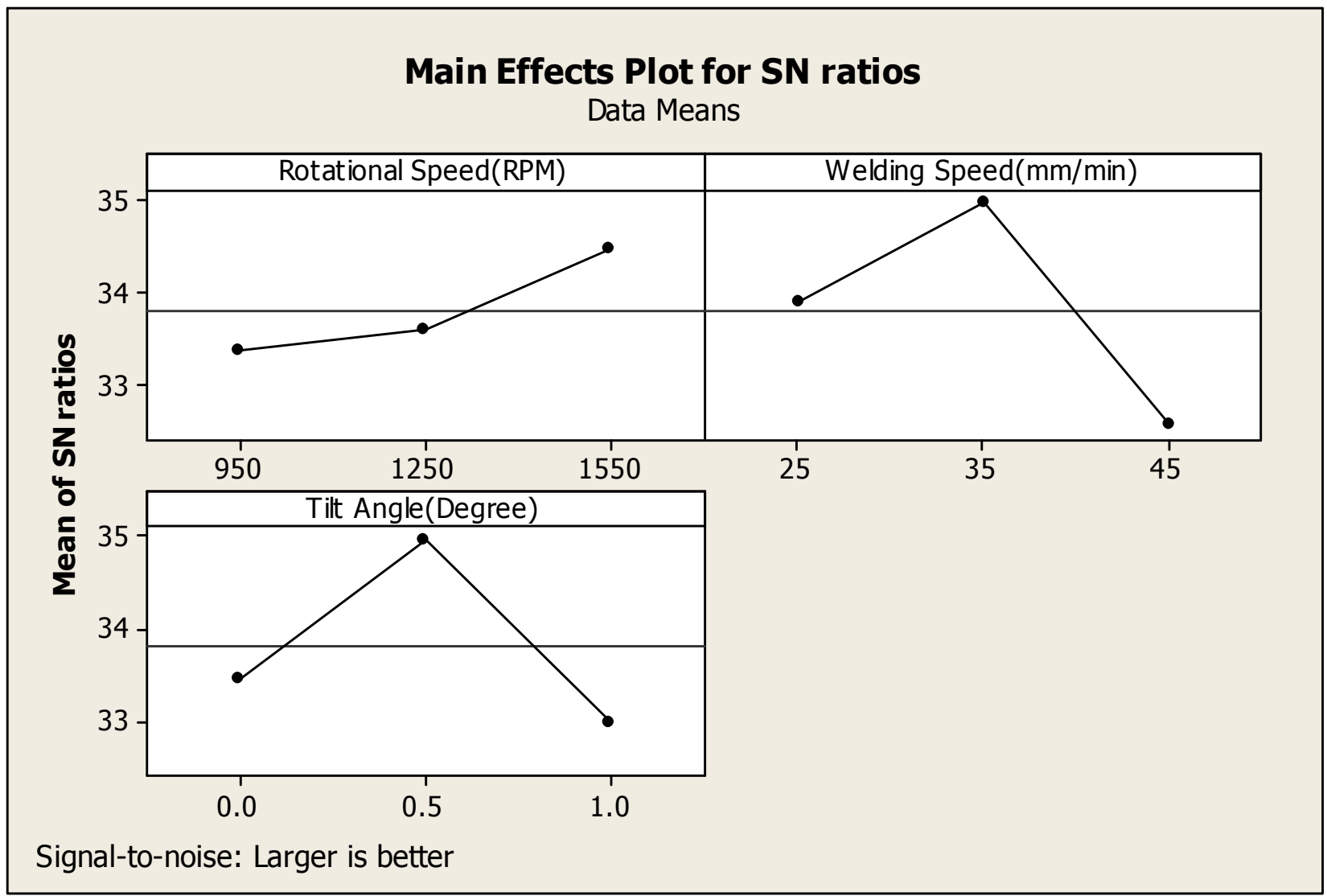

Fig. 4: Mean effect plots for means on Hardness

Figure 4 shows effect of various FSW parameters on the mean of S/N Ratio of plotted utilizing the welding results obtained. From the figure, it is observed that the mean value of the mean of S/N Ratio of VHN rises constantly by increasing the value of rotational speed from 950 to 1250 $\mathrm{rpm}$ and from 1250 to $1550 \mathrm{rpm}$. The mean of S/N Ratio of VHN is increased by increasing the welding speed from 25 to $35 \mathrm{~mm} / \mathrm{min}$ after that the mean of $\mathrm{S} / \mathrm{N}$ Ratio of $\mathrm{VHN}$ is decreased by increasing the welding speed from 35 to 45 $\mathrm{mm} / \mathrm{min}$. The mean of $\mathrm{S} / \mathrm{N}$ Ratio of VHN is increased by increasing the tilt angle from 0 to 0.5 degree after that the mean of S/N Ratio of VHN is decreased by increasing the tilt angle from 0.5 to 1 degree.

Table 4 Response table for Signal to Noise Ratios Larger is better

\begin{tabular}{|l|l|l|l|}
\hline Level & $\begin{array}{l}\text { Rotational } \\
\text { speed(rpm) }\end{array}$ & $\begin{array}{l}\text { Welding } \\
\text { speed(mm/min) }\end{array}$ & $\begin{array}{l}\text { Tilt } \\
\text { angle } \\
\text { (degree) }\end{array}$ \\
\hline 1 & 33.36 & 33.89 & 33.46 \\
\hline 2 & 33.58 & 34.96 & 34.96 \\
\hline 3 & 34.47 & 32.56 & 32.99 \\
\hline Delta & 1.11 & 2.41 & 1.97 \\
\hline Rank & 3 & 1 & 2 \\
\hline
\end{tabular}

Table 4 shows the ranking of FSW parameters for optimizing the hardness of welded joint. It can be observed that welding speed has the largest effect on the hardness of aluminium alloy 6105 . The rotational speed has the smallest effect on the hardness of welded joint.

\section{Estimation of Optimum Performance Characteristics}

For calculating the maximum value of tensile strength, firstly select the maximum value of tool rotational speed. Secondly select the maximum values of welding speed and then select the maximum value of tilt angle.

$$
\text { Tensile Strength }(\mathrm{TS})=\mathrm{N}_{2}+\mathrm{S}_{1}+\mathrm{A}_{1}-2 \mathrm{~T}
$$

Where, $\mathrm{T}=$ overall mean of tensile strength $\mathrm{N}_{2}=$ average tensile strength at second level of tool rotational speed i.e. $1250 \mathrm{rpm}$.

$\mathrm{S}_{1}=$ average tensile strength at first level of welding speed i.e. $25 \mathrm{~mm} / \mathrm{min}$.

$A_{1}=$ average tensile strength at first level of tilt angle of tool i.e. zero degree.

$\mathrm{TS}=0.08433+0.082+0.082666-2 \times 0.07888$

$\mathrm{TS}=0.0912 \mathrm{KN} / \mathrm{mm}^{2}$ 


\section{Estimation of Optimum Performance}

\section{Characteristics}

$$
\text { Vicker Hardness }(\mathrm{VHN})=\mathrm{N}_{3}+\mathrm{S}_{2}+\mathrm{A}_{2}-2 \mathrm{~T}
$$

Where, $\mathrm{T}=$ overall mean of vicker hardness

$\mathrm{N}_{3}=$ average vicker hardness at third level of tool rotational speed i.e. $1550 \mathrm{rpm}$.

$\mathrm{S}_{2}=$ average vicker hardness at second level of welding speed i.e. $35 \mathrm{~mm} / \mathrm{min}$.

$\mathrm{A}_{2}=$ average vicker hardness at second level of tilt angle of tool i.e. 0.5 degree.

$\mathrm{VHN}=53.33+56+56-2 \times 49.77$

$\mathrm{VHN}=65.7$

\section{CONCLUSION}

- It is noted that for the friction stir welding of aluminium alloy 6105 , maximum tensile strength is $0.0912 \mathrm{KN} / \mathrm{mm}^{2}$, which is obtain at $1250 \mathrm{rpm}$ tool rotation speed, $25 \mathrm{~mm} / \mathrm{min}$ welding speed and $0^{0}$ tilt angle

- It is also noted that the maximum Vicker,s hardness is 65.7 which is at $1550 \mathrm{rpm}$ rotational speed, $35 \mathrm{~mm} / \mathrm{min}$ welding speed and $0.5^{\circ}$ tilt angle.

\section{REFERENCES}

[1] Rajkumar, V., Arivazhagan, N. and Devendranath Ramkumar, K. [2014], "Studies on effect of tool design and welding parameters on the friction stir welding of dissimilar aluminium alloys AA 5052 AA 6061," International Journal of Procedia Engineering, Vol. 75, pp. 93-97.

[2] Aydın, Hakan., Bayram, Ali., Uguz, Agah. and Akay, Kemal Sertan. [2008], "Tensile properties of friction stir welded joints of 2024 aluminum alloys in different heat-treated-state," International Journal of Materials and Design, Vol 30, pp. 22112221.

[3] Bisadi, H., Tavakoli, A., Sangsaraki, M. Tour. and Sangsaraki, K. Tour. [2012], "The influences of rotational and welding speeds on microstructures and mechanical properties of friction stir welded Al5083 and commercially pure copper sheets lap joints," International Journal of Materials and Design, Vol 43, pp. 80-88.

[4] Lakshminarayanan, A. K., and Balasubramanian, V. [2008], "Comparison of RSM with ANN in predicting tensile strength of friction stir welding AA7039 aluminium alloy joints," International Journal of Trans. Nonferrous met. Soc. China, Vol. 19, pp. 9-18.

[5] Dhancholia, Divya Deep., Sharma, Anuj. and Vyas, Charit. [2014], "Optimization of friction stir welding parameters for AA 6061 and AA 7039 aluminium alloys by Response Surface Methodology (RSM)," International Journal of Advanced Mechanical Engineering Software, Vol. 4, pp.565-571.
[6] Elatharasan, G. and Senthil kumar, V.S. [2012], "Modelling and optimization of friction stir welding parameters for dissimilar aluminium alloy using RSM," International conference of Proceeding Engineering, Vol 38, pp. 3477-3481.

[7] Jarrah, Al., Jawdat A. and Qahsi, Al., Deya, A. [2013], “Optimization of friction stir welding parameters for joining aluminum alloys using RSM," National Journal of Adv. Theor. Appl. Mech., Vol. 6, pp. 1, 13 -26.

[8] Koilraj, M., Sundareswaran, V. and Koteswara Rao, S.R. [2012], "Friction stir welding of dissimilar aluminum alloys AA2219 to AA5083 optimization of process parameters using Taguchi technique," International Journal of Materials and Design, Vol. 42, pp. 1-7. 